\title{
AN EXTENSION OF KOTZIG'S THEOREM
}

\author{
VAlerit A. Aksenov ${ }^{1}$ \\ Novosibirsk State University, Novosibirsk 630090, Russia \\ e-mail: akc@belka.sm.nsc.ru \\ Oleg V. BORODIN ${ }^{2}$ \\ Institute of Mathematics Siberian Branch \\ Russian Academy of Sciences, Novosibirsk, 630090, Russia \\ e-mail: brdnoleg@math.nsc.ru \\ AND \\ Anna O. IVAnova ${ }^{3}$ \\ Ammosov North-Eastern Federal University Yakutsk, 677000, Russia \\ e-mail: shmgnanna@mail.ru
}

\begin{abstract}
In 1955, Kotzig proved that every 3-connected planar graph has an edge with the degree sum of its end vertices at most 13, which is tight. An edge $u v$ is of type $(i, j)$ if $d(u) \leq i$ and $d(v) \leq j$. Borodin (1991) proved that every normal plane map contains an edge of one of the types $(3,10),(4,7)$, or $(5,6)$, which is tight. Cole, Kowalik, and Škrekovski (2007) deduced from this result by Borodin that Kotzig's bound of 13 is valid for all planar graphs with minimum degree $\delta$ at least 2 in which every $d$-vertex, $d \geq 12$, has at most $d-11$ neighbors of degree 2 .

We give a common extension of the three above results by proving for any integer $t \geq 1$ that every plane graph with $\delta \geq 2$ and no $d$-vertex, $d \geq 11+t$, having more than $d-11$ neighbors of degree 2 has an edge of one of the following types: $(2,10+t),(3,10),(4,7)$, or $(5,6)$, where all parameters are tight.
\end{abstract}

Keywords: plane graph, normal plane map, structural property, weight.

2010 Mathematics Subject Classification: 05C15.

\footnotetext{
${ }^{1}$ The author was supported by grant 15-01-05867 of the Russian Foundation for Basic Research.

${ }^{2}$ The author was supported by grant 16-01-00499 of the Russian Foundation for Basic Research.

${ }^{3}$ The author's work was performed as a part of government work "Organizing research".
} 


\section{REFERENCES}

[1] V.A. Aksenov, O.V. Borodin, L.S. Mel'nikov, G. Sabidussi, M. Stiebitz and B. Toft, Deeply asymmetric planar graphs, J. Combin. Theory Ser. B 95 (2005) 68-78. doi:10.1016/j.jctb.2005.03.002

[2] S.V. Avgustinovich and O.V. Borodin, Neighborhoods of edges in normal maps, Diskretn. Anal. Issled. Oper. 2 (1995) 3-9, in Russian.

[3] O.V. Borodin, On the total coloring of planar graphs, J. Reine Angew. Math. 394 (1989) 180-185.

[4] O.V. Borodin, Joint generalization of the theorems of Lebesgue and Kotzig on the combinatorics of planar maps, Diskret. Mat. 3 (1991) 24-27, in Russian.

[5] O.V. Borodin, Joint extension of two theorems of Kotzig on 3-polytopes, Combinatorica 13 (1993) 121-125. doi:10.1007/BF01202794

[6] O.V. Borodin, The structure of neighborhoods of an edge in planar graphs and the simultaneous coloring of vertices, edges and faces, Mat. Zametki 53 (1993) 35-47, in Russian.

[7] O.V. Borodin and D. Sanders, On light edges and triangles in planar graphs of minimum degree five, Math. Nachr. 170 (1994) 19-24. doi:10.1002/mana.19941700103

[8] O.V. Borodin, Simultaneous coloring of edges and faces of plane graphs, Discrete Math. 128 (1994) 21-33. doi:10.1016/0012-365X(94)90101-5

[9] O.V. Borodin, Structural theorem on plane graphs with application to the entire coloring, J. Graph Theory 23 (1996) 233-239. doi:10.1002/(SICI)1097-0118(199611)23:3〈233::AID-JGT3〉3.0.CO;2-T

[10] O.V. Borodin, More about the weight of edges in planar graphs, Tatra Mt. Math. Publ. 9 (1996) 11-14.

[11] O.V. Borodin, A.V. Kostochka and D.R. Woodall, List edge and list total colourings of multigraphs, J. Combin. Theory Ser. B 71 (1997) 184-204. doi:10.1006/jctb.1997.1780

[12] O.V. Borodin, A.O. Ivanova, A.V. Kostochka and N.N. Sheikh, Minimax degrees of quasiplanar graphs with no short cycles other than triangles, Taiwanese J. Math. 12 (2008) 873-886.

[13] O.V. Borodin, A.V. Kostochka, N.N. Sheikh and G. Yu, M-degrees of quadranglefree planar graphs, J. Graph Theory 60 (2009) 80-85. doi:10.1002/jgt.20346

[14] O.V. Borodin, Colorings of plane graphs: A survey, Discrete Math. 313 (2013) $517-539$. doi:10.1016/j.disc.2012.11.011 
[15] O.V. Borodin and A.O. Ivanova, Low edges in 3-polytopes, Discrete Math. 338 (2015) $2234-2241$. doi:10.1016/j.disc.2015.05.018

[16] O.V. Borodin and A.O. Ivanova, The vertex-face weight of edges in 3-polytopes, Sibirsk. Mat. Zh. 56 (2015) 338-350, in Russian.

[17] R. Cole, Ł. Kowalik and R. Škrekovski, A generalization of Kotzig's theorem and its application, SIAM J. Discrete Math. 21 (2007) 93-106. doi:10.1137/050646196

[18] Z. Dvořák and R. Škrekovski, A theorem about contractible and light edge, SIAM J. Discrete Math. 20 (2006) 55-61. doi: $10.1137 / 05062189 \mathrm{X}$

[19] B. Ferencová and T. Madaras, Light graphs in families of polyhedral graphs with prescribed minimum degree, face size, edge and dual edge weight, Discrete Math. 310 (2010) 1661-1675.

doi:10.1016/j.disc.2009.11.027

[20] Ph. Franklin, The four color problem, Amer. J. Math. 44 (1922) 225-236. doi: $10.2307 / 2370527$

[21] B. Grünbaum, New views on some old questions of combinatorial geometry, in: Proc. Colloq. Int. sulle Theorie Combinatorie, Rome, 1973, Vol. 1 (Accad. Naz. dei Lincei, 1976) 451-468.

[22] P. Hudák and T. Madaras, On doubly light triangles in plane graphs, Discrete Math. 313 (2013) 1978-1988. doi:10.1016/j.disc.2012.11.018

[23] S. Jendrol' and T. Madaras, On light subgraphs in plane graphs of minimum degree five, Discuss. Math. Graph Theory 16 (1996) 207-217. doi:10.7151/dmgt.1035

[24] S. Jendrol' and M. Maceková, Describing short paths in plane graphs of girth at least 5, Discrete Math. 338 (2015) 149-158. doi:10.1016/j.disc.2014.09.014

[25] S. Jendrol', M. Maceková and R. Soták, Note on 3-paths in plane graphs of girth 4, Discrete Math. 338 (2015) 1643-1648. doi:10.1016/j.disc.2015.04.011

[26] S. Jendrol' and H.-J. Voss, Light subgraphs of graphs embedded in the plane - A survey, Discrete Math. 313 (2013) 406-421. doi:10.1016/j.disc.2012.11.007

[27] A. Kotzig, Contribution to the theory of Eulerian polyhedra, Mat.-Fyz. Cas. (Math. Slovaca) 5 (1955) 101-113, in Slovak.

[28] A. Kotzig, From the theory of Eulerian polyhedrons, Mat.-Fyz. Čas. (Math. Slovaca) 13 (1963) 20-31, in Russian. 
[29] H. Lebesgue, Quelques conséquences simples de la formule d'Euler, J. Math. Pures Appl. (9) 19 (1940) 27-43.

[30] T. Madaras and R. Škrekovski, Heavy paths, light stars, and big melons, Discrete Math. 286 (2004) 115-131.

doi:10.1016/j.disc.2003.11.052

[31] J. Nešetřil, A. Raspaud and E. Sopena, Colorings and girth of oriented planar graphs, Discrete Math. 165/166 (1997) 519-530. doi:10.1016/S0012-365X(96)00198-7

[32] P. Wernicke, Über den kartographischen Vierfarbensatz, Math. Ann. 58 (1904) 413-426.

doi:10.1007/BF01444968

Received 9 October 2015

Revised 6 January 2016

Accepted 6 January 2016 